\title{
English Today and Tomorrow
}

\author{
Ryodo OGATA
}

1. Introduction

The first edition of Kenkyusha's New English-Japanese Dictionary, published in 1960, had back mirror with the meaning of 'rear-view. mirror', which was blamed as an error by many people.

It was a typical Japanese English. But nowadays we find someJapanese English accepted as loan words into English.

This paper investigates some of the features reflected in modern English with a special reference to economical brevity.

\section{Economy}

\subsection{Economy in pronunciation}

Haplology, like pronouncing 'probably' as 'probly', or 'humblely' as 'humbly, is a traditional phenomenon.

But today we hear many shortened or, I may say, economical pronunciations: 'eighth' is pronounced [ei $\left.\theta^{\prime}\right]$.

For a linguist P.H. Matthews, '-ire-' of 'wireless' is monophthongal: 
In my speech, the -ire- of wireless would normally be monophthongal. But I cannot swear that I never use a triphthong. (P.H. Matthews. Generative Grammar and Linguistic Competance. p.44.)

\subsection{Omission of initial sounds}

Prosiopesis is a natural phenomenon reflecting the modern forms of language. Thus we have:

I am going home tomorrow. > Am going home tomorow.

It looks like rain. > Looks like rain.

It is... > It's... > 'T's. . .

American little kids say 'cause meaning because because they don't notice the initial sound in adults' speech.

In the greetings, if one says 'A Merry Christmas and a HappyNew Year', he may sound odd. 'Merry Christmas', 'Happy New Year' or 'Merry Christmas and a Happy New Year' are the common forms.

In the next example, 'uns is the short form of 'ones' with the omitted half-vowel $[\mathrm{w}]$ :

In this affluent age, young 'uns don't want to take on the challenge... (The Daily Yomiuri, Dec. 1986)

2.3. Shortening of words

When my American brother taught me $\mathrm{fig}^{(1)}$ as a short form of refrig-

(1)The first citation of frig was, according to OED, in 1929 in the form of 'frig. 
erator, I couldn't believe it thinking that fridge is the shortest form to retain the $\left[\mathrm{d}_{3}\right]$ sound. But if you think it out, you'll see that ' $\mathrm{g}$ ' is pronounced $\left[\mathrm{d}_{3} \mathrm{i}\right]$ in the English Alphabet. So, as a convention we have, in the dictionary, frig ${ }^{1}$ [frig] and frig $^{2}$. [frid 3]. And frig is shorter and thus more economical than fridge.

In the same way, we have the convention of thru (through), donut (doughnut), nite (night), comfy (comfortable), fave (favorite), telly (television), phone (telephone).

As the general rule, the stressed part (as core) remains like fridge, telly, but we have a unique example of copter (helicopter), where the unstressed part remained.

\subsection{Omission of words}

At a restaurant we ask for 'Two waters' (Two glasses of water) 'Three beers' (Three mugs of beer), etc.

American English omits 'to' in a sentence, 'A message was sent (to) him.' or in a phrase, 'the money due (to) him'. (1)

Also in the use of 'ought', American English uses bare infinitive in a negative and interrogative sentences.

'You oughtn't smoke so much'

'Ought you smoke so much?'(2)

American English also omits 'at' in the phrase 'to stay (at) home.' In the 'so...that' construction, that's are usually omitted in modern

(1)Zandvoort (1975), §596.

(2)Quirk, Greenbaum (1973), p.37. 
speech or writing.

Conjunction that is also omitted in the example below:

The second purpose is to explain why it was (that) they decided to undertake this project. (Terms in Systemic Linguistics: $A$ Guide to Halliday)

Conjunction when is also omitted in the following:

The last time (when) prices were uniform was June 1976. (The Japan Times)

$\cdots$ the antihegemony issue has been batted back and forth like a ping -pong ball during the past several months (when or in which) the Sino-Japanese talks have been going on. (Editorial of The Japan Times, June 25, 1975)

The omission of of in 'a couple of' or the omission of contextuallyunderstood words is explained in The Random House Dictionary of the English Language. (s.v. couple):

The shortened phrase A COUPLE, without OF (The gas station is a couple miles from here), is an Americanism of recent development that occurs chiefly in informal speech or representations of speech. Without a following noun, the phrase is highly informal: Jack shouldn't drive. I think he's had a couple. (Here the noun drinks is omitted.) 


\section{Brevity}

\subsection{Who vs, whom}

Today, one hardly hears 'Whom did you meet yesterday?' Instead, 'Who did you meet yesterday?' is the standard form. This particular form is explained by that the initial position of a sentence is the subject position, so that whom is taken place by the nominative case of who.

Some drastic scholars argue that whom will be taken place by who entirely.

Once 'It's me' had a hot discussion, but you can hardly meet a person who says 'It's I' nowadays.

Me as a subject has found some ground for many people so that you even hear 'Me did it', though this is condemned as vulgar English.

In the verse of Diana Ross' song If We Hold On Together, we hear two lines 'clouds roll by for you and I'. This $I$ looks like an example of hypercorrection, but if we look at the lyrics or listen to them more carefully, we notice that $I$ was intentionally used to rhyme with the previous line 'our dreams will never die.' i.e. '... and $I$ ' ends with [daI], too.

\subsection{Split infinitives}

Split infinitives have been traditionally condemned. But we see nowadays many examples of split infinitives:

Would you be able to please call back later? 
She asked me to please call everyone to the table.

He needs to fully understand the pitfalls.

How I want to always have you near me.

She was able to also acquire a natural use of nodding.

-.to not be oneself (cf. I'm not myself today.) ${ }^{(3)}$

the desire to more completely satisfy our needs

To lightheartedly help illustrate his point, he cited two recent events.

Even a noun can split an infinitive for brevity:

They worked hard in trying to toilet train the child.

Kane(1983) writes 'Phrases and clauses used to split an infinitive are invariably awkward: *' to on the other hand see $^{3(4)}$

But McCrum writes '... if the Genius of the Language finds the split infinitive useful to express certain shades of thought, we can safely guess that all opposition to it will be futile. ${ }^{(5)}$

(3)Redfern (1984) p.103.

(4)Kane (1983) p.711.

(5)McCrum (1986) p.13. 
So we find such an example with an adverbial phrase as:

It seems like we will be able to for a change enjoy a relaxed holiday. (The Daily Yomiuri, Dec. 25, 1987)

There is an interesting title of a book: How to Library Research, where Library Research is originally a noun phrase, but then research is used as a verb also.

\section{String compounds}

What are called string compounds or group adjectives are useful modern device.

the soon-to-be-tested French nuclear bomb

Shintaro Ishihara, novelist-turned-politician

Copies will be mailed on a first-come-first-served basis until we have no more.

a you're-kidding-me attitude

a don't-ask-me look

Asked by pressmen how were the conversations with world leaders, president-elect Bill Clinton said:

"They (the conversations with the world leaders) were all very $I$ - 
look-forward-to-working-with-you conversations."

(The Daily

Yomiuri, Nov. 7, 1992)

All these cases are making use of string compounds for brevity or convenience.

The length of these compounds is a problem. In the written form it can be long, for one can tell, at sight, that it is a string compound. For example:

I'll-go-where-you-go-do-what-you-do-be-what-you-are-and-I'llbe-happy philosophy worked out splendidly for Mother. (B. MacDonald: The Egg and I.)

\section{Loan words}

The amount of loan words greatly depends on the political and/or economical power of the country giving loan words to the other country. English vocabrary increased in the history through the Norman Conquest of 1066 .

Today Japan has much economical power and thus is giving Japanese or Japanese English to the English language.

Zaibatsu, dango, yakuza are typical ones. Salaryman, skinship, nighter are Japanese English, but they seem to be being accepted, for they are brief and understandable not like backmirror.

\section{Spelling change}

Recently, many Americans write thankyou. They are now considering it as one word of greetings. Of course, thankyou is pronounced in two 
ways: thânkyou and thankyóu according to the situations.

Likewise, we see anymore, eachother, for awhile. For awhile has already been accepted as standard English.

We find PRONUNCIATION SPELLING like menshun (mention), wimin (women).

\section{Pronunciation change}

Houses is pronounced [hausi:z] instead of [hauzi:z], but it is not mentioned in any pronouncing dictionary yet.

8. Transitives vs. intransitives

In the English text books used in high schools and colleges in the United States, we find drills on lay vs. lie. Yet, even American presidents make mistakes and say 'Lay down, John'.

In the next examples, transitives are used as intransitives, which can be called ACTIVO-PASSIVE use.

the consonant string will then simplify to [...ipi]

(Chomsky and Halle, The Sound Pattern of English, p.148)

a double consonant in the underlying form, which then simplifies by rule (156)

(Chomsky and Halle, The Sound Pattern of English, p.149)

These slot machines use pennies, nickels, dimes, ...

(W.W. Smith, Carefree English, p.14) 
Numerous other groups in Africa, aboriginal America, and elsewhere called themselves by terms that translate the wealthy ones, the intelligible ones, or as the Navaho, simply people. (I.C. Brown, Understanding Other Cultures. p.4.)

Some Japanese words like 'wabi' or 'sabi' don't translate well into English.

\section{Conclusion}

We have investigated many aspects of modern English, many of which reflect ways to cope with the busy life of the modern world. Split infinitives and compounds are also devices for brevity and compactness.

In some cases the difference between transitive verbs and intransitive verbs is disappearing so long as there won't be misunderstandings.

They may certainly be convenient, but my fear is that these trends might destroy the beauty of the English language.

\section{References}

Araki, Kazuo and Minoru Yasui. 1992. Sanseido's New Dictionary of English Grammar. Tokyo: Sanseido.

Kane, T. S. 1983. The Oxford Guide to Writing. Oxford: Oxford University Press.

McCrum, R. ,William Cran, Robert MacNeil. 1986. The Story of English. London: Faber and Faber.

Ogata, Ryodo. 1976. "Compound Adjectives in English" Artes Liberales. 
Morioka: Iwate University .

Ogata, Ryodo. 1986. "Eigohyogen no kansoka ni tsuite" (Simplification in English) Thought and Culture. Morioka: Europian Studies at Iwate University.

Quirk, Randolph and Sidney Greenbaum. 1973. A University Grammar of English. London: Longman.

Redfern, Walter D. 1984. Puns. New York: Basil Blackwell.

Zandvoort, R. W. 1975. A Handbook of English Grammar. Tokyo: Maruzen.

（東北芸術工科大学勤務） 